\title{
Laju Sedimentasi pada Tampungan Bendungan Tugu Trenggalek
}

\author{
Faradilla Ayu Rizki Shiami, Umboro Lasminto, dan Wasis Wardoyo \\ Departemen Teknik Sipil, Fakultas Teknik Sipil dan Perencanaan, Institut Teknologi Sepuluh Nopember (ITS) \\ e-mail: umboro_lasminto@ce.its.ac.id
}

\begin{abstract}
Abstrak-Hal terpenting dalam perencanaan waduk selain desain hidrolis bendungan adalah sedimentasi. Sedimen yang mengendap di waduk merupakan faktor pembatas kapasitas tampungan efektif waduk, sehingga jumlah sedimen di waduk biasa digunakan untuk menetapkan masa guna waduk. Prediksi sedimentasi yang terjadi pada waduk dilakukan dengan memperhitungkan besar laju sedimentasi berdasarkan metode perhitungan analitik, namun untuk mempermudah dalam menggambarkan sedimentasi yang terjadi pada waduk dilakukan metode pemodelan menggunakan software HEC-RAS. Program HEC-RAS sendiri merupakan salah satu program pemodelan analisis angkutan sedimen pada saluran maupun sungai. Tujuannya adalah untuk memprediksi besar laju sedimentasi pada Waduk Tugu dengan metode perhitungan analitik dan pemodelan software HEC-RAS, kemudian kedua hasilnya dibandingkan. Pada perhitungan maupun pemodelan sedimentasi menggunakan HEC-RAS data yang dibutuhkan adalah data geometri sungai, data hidrolika, debit sungai, dan parameter sedimen. Pemodelan sedimentasi dengan HEC-RAS dilakukan dengan mencoba beberapa model. Pemodelan pertama berupa sungai dan tubuh bendung. Pemodelan kedua dengan penambahan ambang pelimpah. Pemodelan ketiga, sungai yang dimodelkan hanya alur sungai bagian hilir. Pemodelan keempat penambahan culvert sebagai saluran pengambilan. Pemodelan kelima dengan menambah lateral inflow pada hulu tubuh bendung sebagai alternatif lain untuk memodelkan saluran pengambilan. Pemodelan keenam sama dengan pemodelan keempat namun dengan debit inflow pertama yang dibesarkan sebagai asumsi bahwa waduk terisi penuh baru dioperasikan. Perhitungan analitik dihitung dengan metode total load Laursen yang juga digunakan dalam pemodelan HEC-RAS dan dihitung pada penampang melintang bagian hulu. Hasil perhitungan analitik berupa besar angkutan sedimen yang kemudian dibandingkan dengan pemodelan HEC-RAS. Angkutan sedimen hasil dari perhitungan analitik cenderung lebih kecil daripada hasil dari pemodelan HEC-RAS, dimana perkiraan besar laju sedimentasi dari metode pemodelan HEC-RAS sebesar 22.000 $\mathrm{m}^{3} /$ th sedangkan laju sedimentasi hasil perhitungan analitik sebesar $19.400 \mathrm{~m}^{3} / \mathrm{th}$. hal ini dikarenakan penyederhanaan geometri penampang pada perhitungan analitik, sedangkan geometri pada model lebih detail.
\end{abstract}

Kata Kunci-Perhitungan Analitik, Sedimentasi, Software HECRAS, waduk.

\section{PENDAHULUAN}

B endungan Tugu terletak di Sungai Keser, Desa Nglinggis, Kecamatan Tugu, Kabupaten Trenggalek, Propinsi Jawa Timur. Secara geografis bendungan ini terletak pada posisi $111^{\circ} 34^{\prime}-111^{\circ} 37^{\prime}$ Bujur Timur dan $8^{\circ} 1^{\prime}-8^{\circ} 3^{\prime}$ Lintang Selatan. Luas daerah aliran sungai di lokasi bendungan sebesar 43,06 $\mathrm{km}^{2}$ dengan panjang sungai $9.295 \mathrm{~km}$. Bendungan Tugu dibangun dengan tujuan sebagai pengendali banjir, reservoir (tampungan air), pemenuhan kebutuhan air baku, PLTMH, dan pariwisata serta konservasi air dan hayati (Gambar 1) [1].

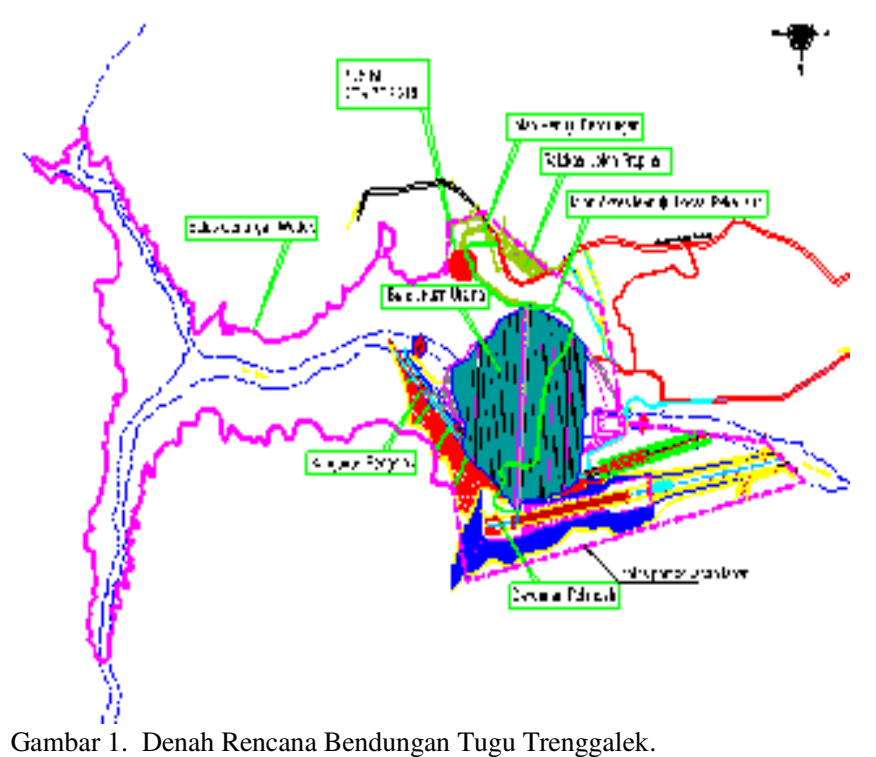

Perencanaan bendungan selain desain hidrolis bendungan salah satu hal penting yang harus diperhatikan adalah sedimentasi. Konsekuensi dari penampungan air sungai adalah ikut tertampungnya sedimen yang terbawa oleh air. Sedimen yang mengendap di waduk merupakan salah satu faktor pembatas kapasitas tampungan efektif waduk, sehingga jumlah sedimen di waduk biasa digunakan untuk menetapkan masa guna waduk [2].

Prediksi laju sedimentasi yang terjadi pada tampungan bendungan dilakukan dengan metode perhitungan analitik angkutan sedimen yang telah ada, dan untuk mempermudah dalam menggambarkan profil muka air dan sedimentasi yang terjadi pada bendungan maka digunakan software HEC-RAS. Program HEC-RAS merupakan salah satu program pemodelan analisis hidrolika aliran pada saluran maupun sungai yang memiliki empat perhitungan hidrolika satu dimensi dimana salah satunya adalah hitungan transpor sedimen [3].

\section{METODOLOGI}

Langkah-langkah yang dilakukan dalam memprediksi laju sedimentasi pada Waduk Tugu adalah sebagaimana Gambar 2 berikut. 


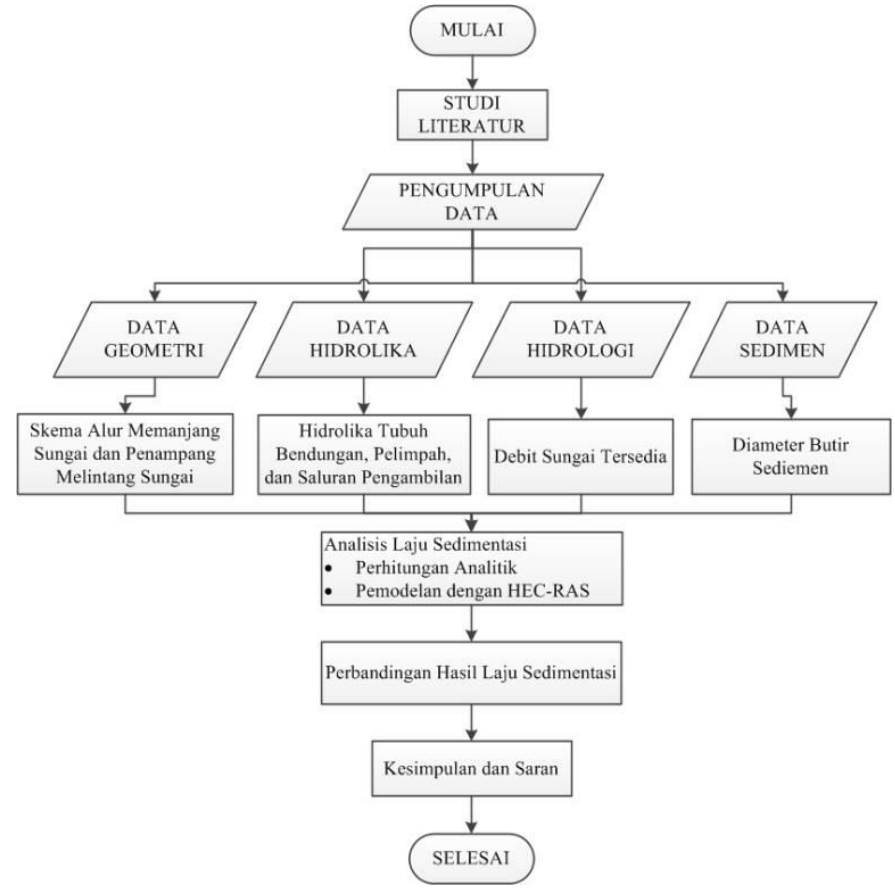

Gambar 2. Diagram Alir Prediksi Laju Sedimentasi.

\section{HASIL DAN PEMBAHASAN}

\section{A. Pemodelan dengan Software HEC-RAS}

1. Data Geometri

Data geometri awal berupa data kontur dengan format dwg. File geometri yang dibutuhkan adalah berformat xyz agar dapat diinputkan ke software Global Mapper untuk mendapat koordinat cross section sungai. Langkah pertama, file tersebut di-export ke format dxf dengan software Autocad. Kemudian dengan software DXF2XYZ file diconvert ke format xyz. Data kontur berformat xyz yang dimasukkan ke Global Mapper dan akan tampak pada Gambar 3 dan Gambar 4.

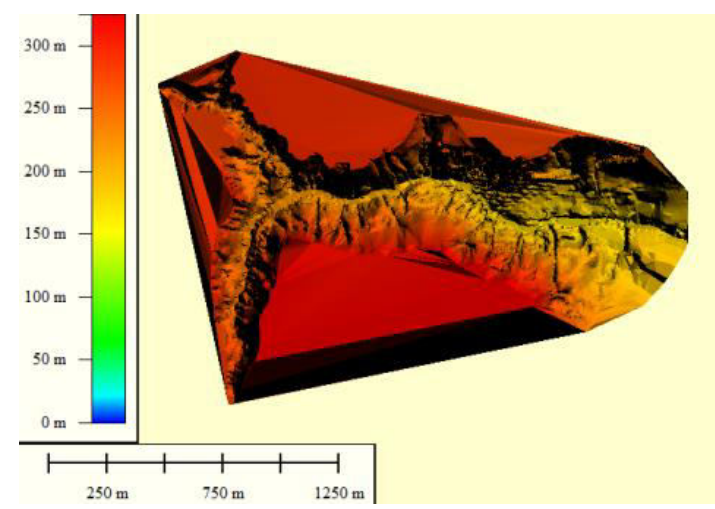

Gambar 3. Kontur Sungai pada Global Mapper.

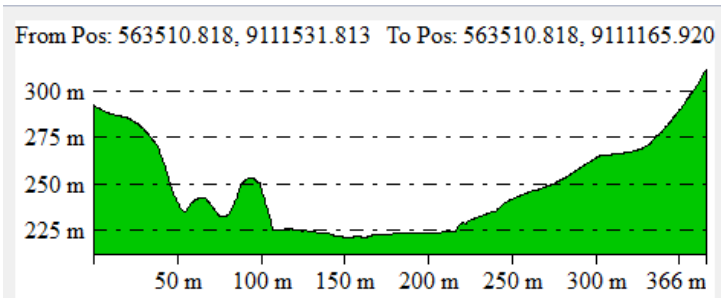

Gambar 4. Hasil cross section pada salah satu river station
Data setiap cross section dimasukkan ke HEC-RAS dengan parameter lain yang dibutuhkan seperti jarak antar cross section, koefisien Manning, dan stuktur melintang sungai dalam hal ini adalah bendungan. Setelah semua data dimasukkan maka geometric data pada HEC-RAS akan tampak pada Gambar 5.

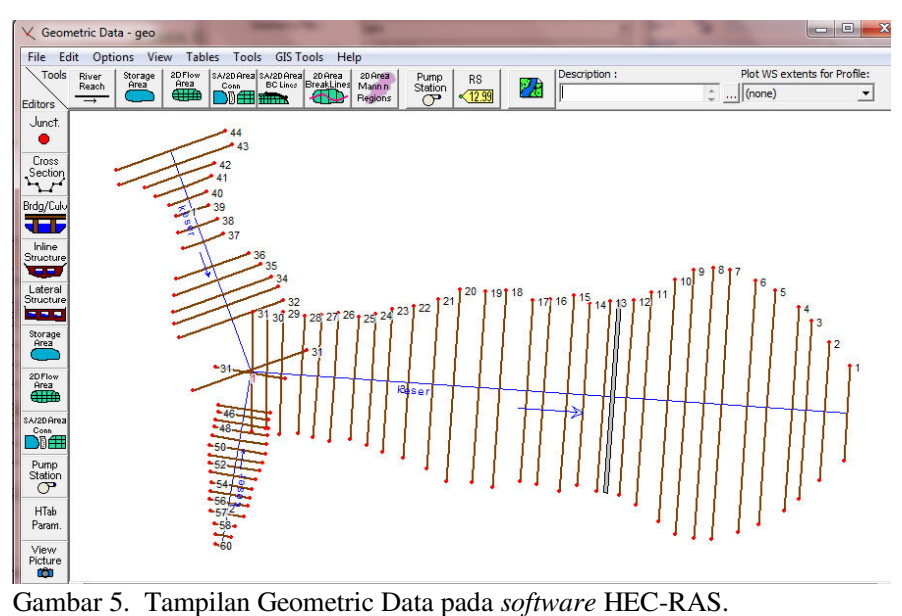

\section{Data Quasi-Unsteady Flow}

Data yang dimasukkan pada flow series merupakan data debit bulanan selama 34 tahun dari tahun 1976-2009 dengan computation increment setiap 24 jam (Gambar 6). Sedangkan kondisi batasan untuk daerah hulu diatur normal depth. Selain itu juga diperlukan data temperatur yang diasumsikan pada suhu normal $25^{\circ} \mathrm{C}$.

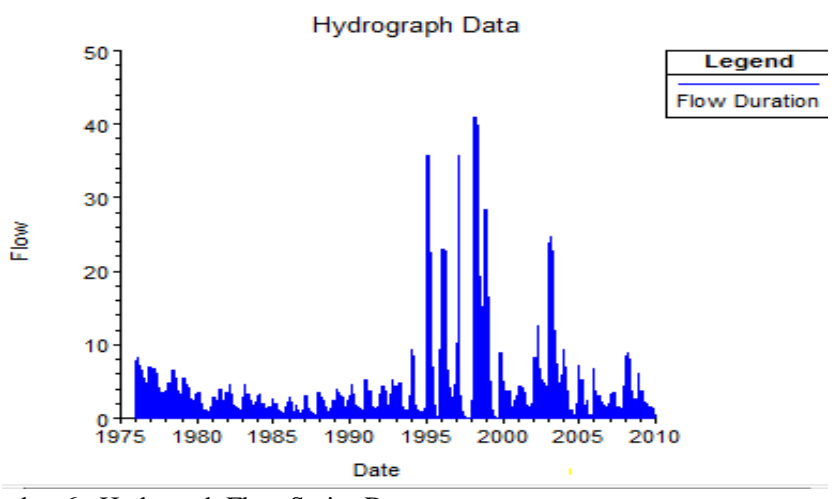

Gambar 6. Hydrograh Flow Series Data.

3. Data Sedimen

Data sedimen adalah data ukuran butiran (Gambar 7). 

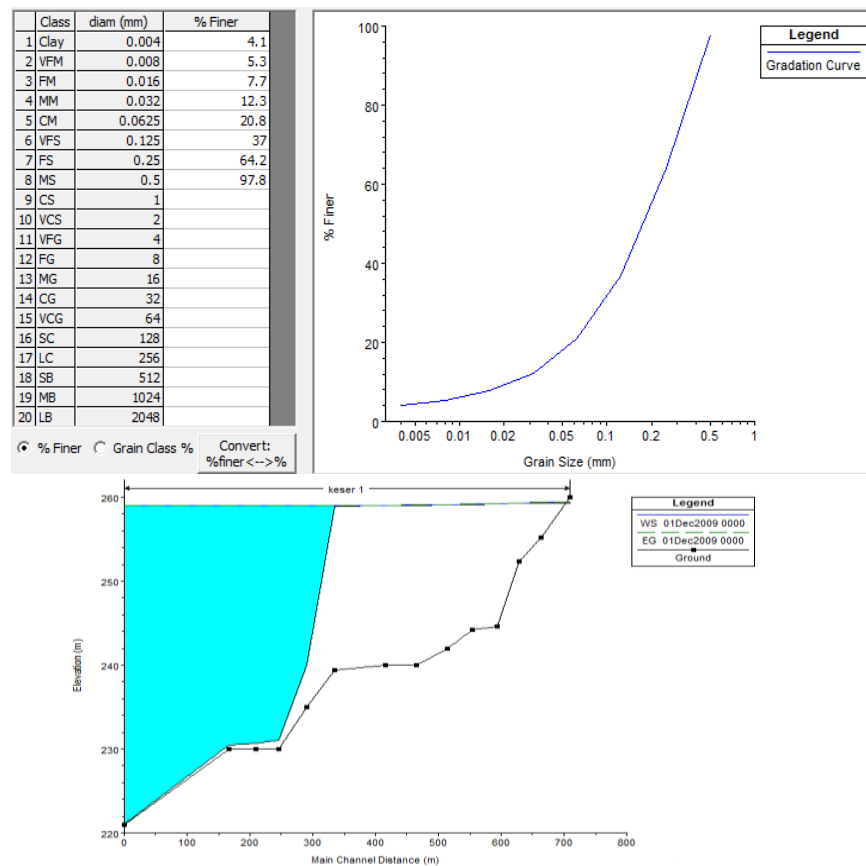

Gambar 8. Profile Plot Reach 1 pada tahun ke 34.

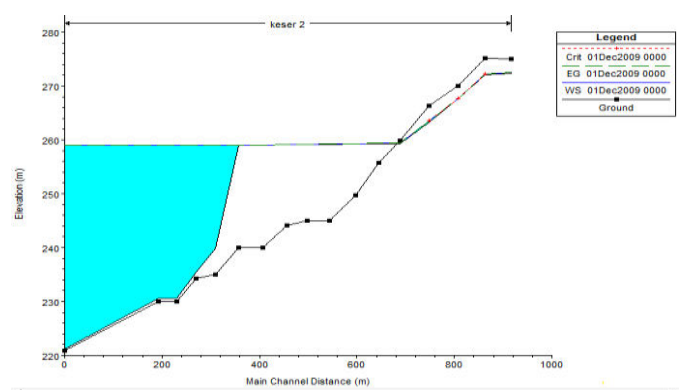

Gambar 9. Profile Plot Reach 2 pada tahun ke 34.

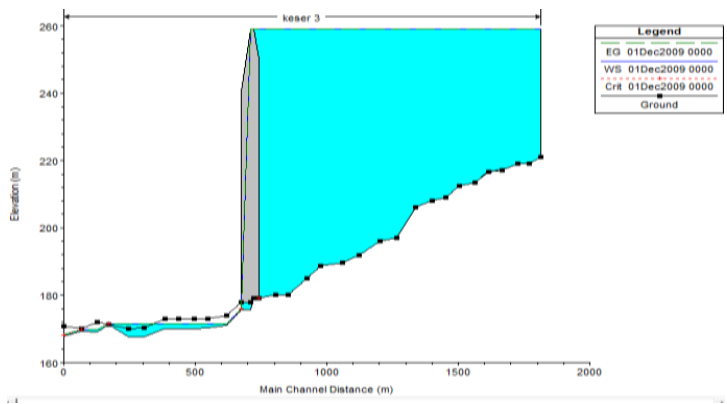

Gambar 10. Profile Plot Reach 3 pada tahun ke 34.

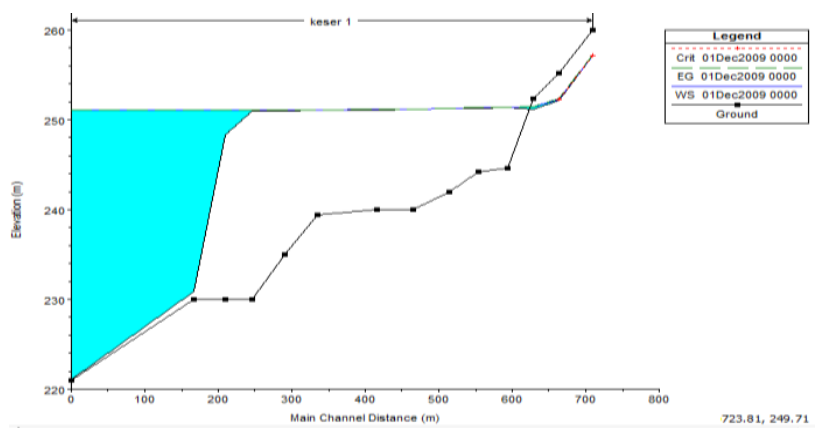

Gambar 11. Profile Plot Reach 1 Tahun ke 34 Setelah Penambahan Pelimpah.
Gambar 7. Data ukuran butir sedimen.

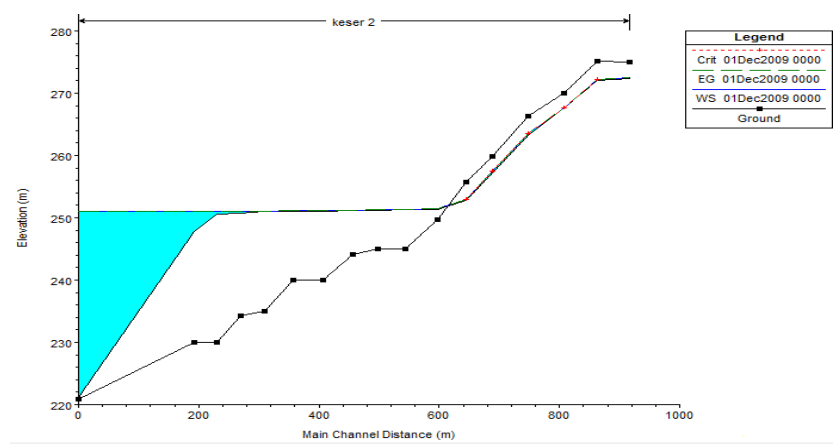

Gambar 12. Profile Plot Reach 2 Tahun ke 34 Setelah Penambahan Pelimpah. 


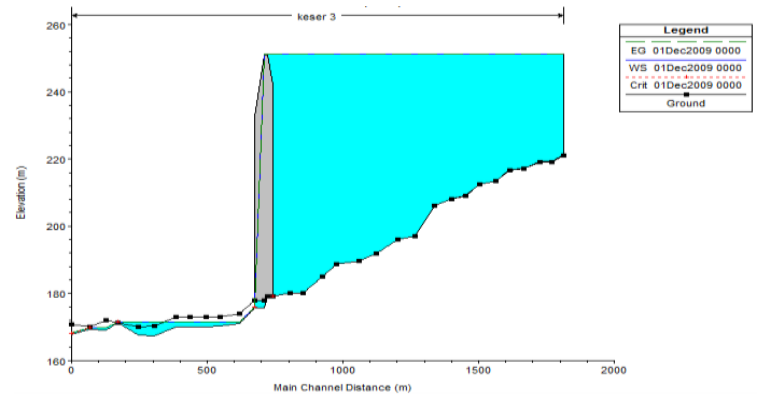

Gambar 13. Profile Plot Reach 3 Tahun ke 34 Setelah Penambahan Pelimpah.

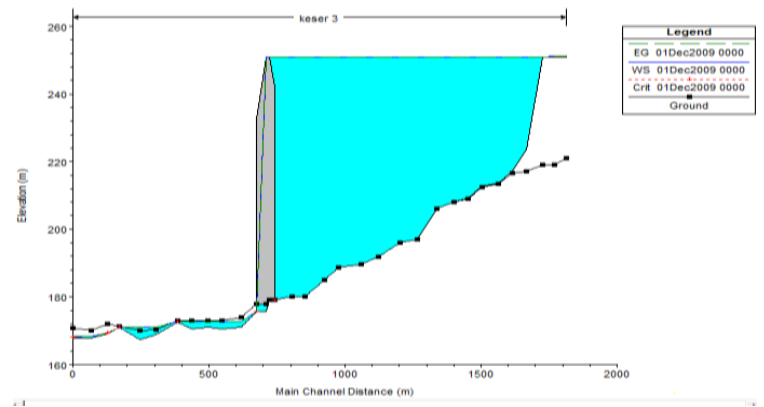

Gambar 14. Profile Plot tahun ke 34dari Pemodelan Ketiga.

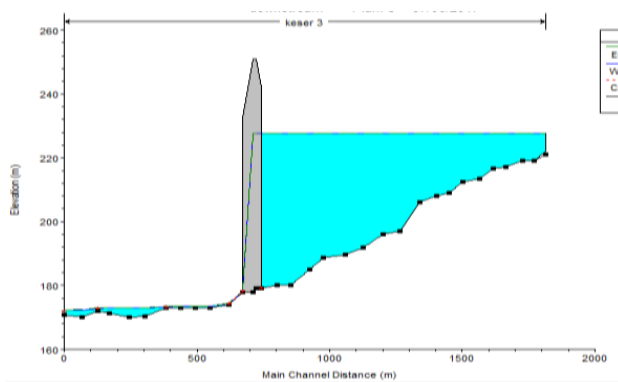

Gambar 15. Profile Plot Tahun ke-1 dari Pemodelan Keempat.

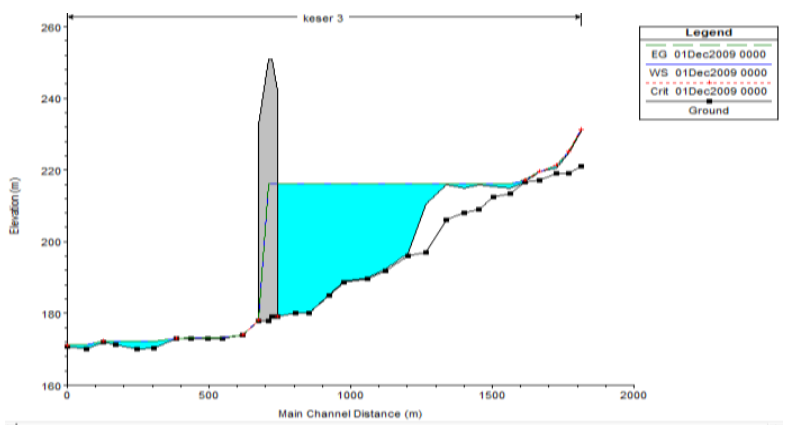

1. Pemodelan keempat dimodelkan dengan penambahan saluran pengambilan berbentuk lingkaran dengan diameter 1 meter pada station bendungan. Penambahan saluran pengambilan ini dimodelkan dengan input culvert pada RS bendungan, dengan cara memilih menu culvert pada kotak editorInline Structure Data. Pada Sediment Data juga dilakukan perubahan pada Max Depth menjadi 0 m. Pada pemodelan ini input culvert dimaksudkan agar ada kecepatan pada daerah hilir sehingga terjadi sedimentasi hingga bagian hilir. Output dari pemodelan ini tampak sedimentasi lebih ke hilir pada bagian sebelumnya namun pada running waktu pertama air waduk turun, sedangkan pada prinsipnya air waduk diisi dulu hingga penuh lalu kemudian dioperasikan (Gambar 15 dan Gambar 16)

2. Pemodelan kelima dengan memasukkan debit lateral pada
Gambar 16. Profile Plot Tahun ke-34 dari Pemodelan Keempat.

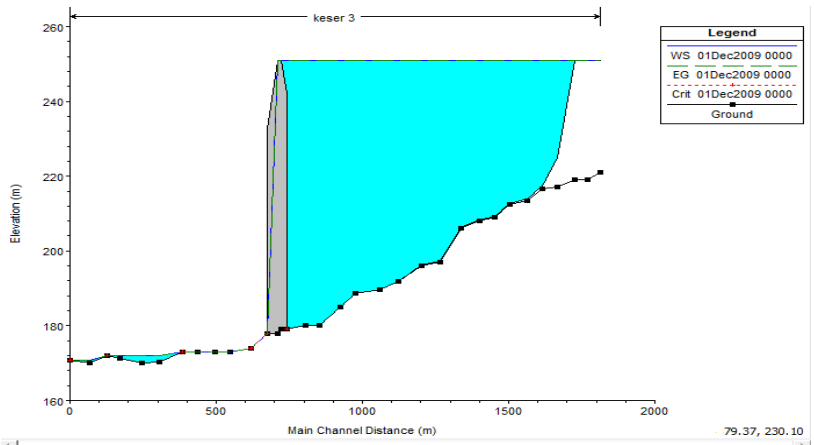

Gambar 17. Profile Plot Tahun ke-34 dari Pemodelan Kelima.

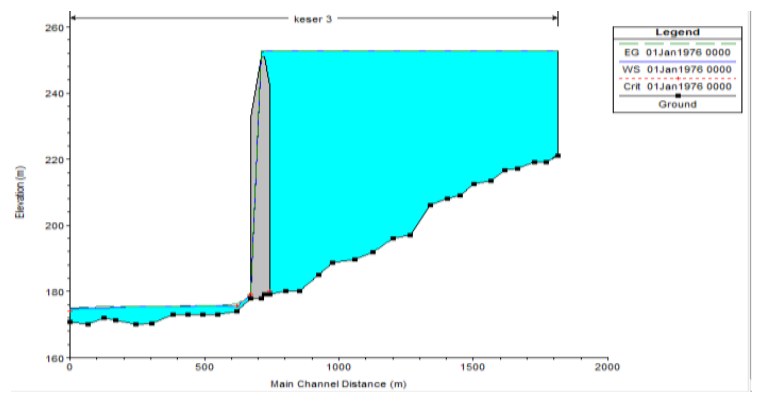

Gambar 18. Profile Plot Tahun ke-1 dari Pemodelan Keenam.

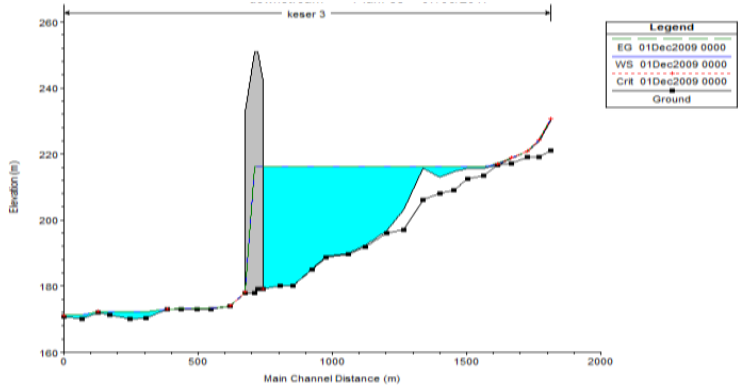

Gambar 19. Profile Plot Tahun ke-34 dari Pemodelan Keenam.

River Station hulu bendungan yaitu River Station 13. Besar debit lateral yaitu besar debit pengambilan namun dengan tanda negatif, sebagai penanda pengganti saluran pengambilan yaitu $-0,7 \mathrm{~m} 3 / \mathrm{dt}$. Sedangkan saluran pengambilan yang dimodelkan dengan circular culvert pada pemodelan sebelumnya tidak digunakan dalam pemodelan kelima ini (Gambar 17).

3. Pemodelan keenam dilakukan dengan memodelkan saluran pengambilan sebagaimana pemodelan keempat, namun yang membedakan adalah pada data flow series debit pertama diperbesar hingga $100 \mathrm{~m} 3 /$ detik. Hal ini dilakukan dengan asumsi air waduk diisi dulu sampai penuh baru dioperasikan. Sehingga model pada profil pertama berupa waduk yang penuh airnya. Pemodelan keenam di 
menghasilkan output yang tidak berbeda jauh dari pemodelan keempat, dimana sedimentasi terjadi hingga hampir di hulu bendungan (Gambar 18 dan Gambar 19)

Pada pemodelan ini dipilih metode angkutan sedimen fungsi Laursen data variabel dari persamaan ini tersedia dan kondisi diameter sedimen yang ada sesuai dengan Laursen yang diperuntukkan untuk pasir halus sampai lanau.

\section{B. Output Running Sediment Analysis}

4. Pemodelan pertama terlihat sedimentasi yang terjadi hanya pada reach hulu, sedangkan pada reach bagian hilir (setelah percabangan) tidak terjadi sedimentasi. Hal ini dikarenakan kecepatan pada reach tersebut bernilai nol, sehingga tidak ada pula sedimentasi pada reach tersebut (Gambar 8-10).

5. Pada pemodelan kedua ini dimodelkan pelimpah dengan cara merubah elevasi tubuh bendungan sesuai elevasi ambang pelimpah yaitu $+251,00$ dan pada station sepanjang lebar ambang yaitu 22 meter dengan tujuan agar kecepatan di bagian hulu tersebut tidak bernilai nol, namun ternyata output yang terjadi masih sama dengan pemodelan pertama dimana tidak ada sedimentasi di reach hilir(Gambar 11-13)

6. Pemodelan ketiga dimodelkan dengan reach hilir saja, hal ini dengan maksud bahwa tidaknya adanya pada pemodelan sebelumnya dikarenakan percabangan yang ada. Hasil pemodelan ini tampak sedimen namun sangat kecil dan hanya pada bagian hulu, sedangkan pada bagian hilir yang dekat dengan bendungan tidak ada sedimentasi (Gambar 14).

\section{Perhitungan Analitik}

Angkutan sedimen total pada tugas ini dihitung menggunakan persamaan Laursen sebagaimana yang sudah dijelaskan sebelumnya, bahwa rumus ini dipilih karena data dari variabel yang dibutuhkan tersedia dan ukuran diameter sedimen sesuai dengan persamaan ini dimana untuk ukuran partikel jenis pasir hingga lanau. Konsentrasi sedimen dengan metode Laursen dihitung dengan persamaan berikut [4]:

$$
\mathrm{C}_{\mathrm{t}}=0.01 \gamma\left(\frac{\mathrm{d}_{50}}{\mathrm{D}}\right)^{7 / 6}\left(\frac{\tau^{\prime}}{\tau \mathrm{ci}}-1\right) \mathrm{f}\left(\frac{\mathrm{U}_{*}}{\omega_{\mathrm{i}}}\right)
$$

dimana $\gamma=$ berat jenis air

$\mathrm{di}=$ ukuran partikel sedimen berpresentase $\mathrm{i} \%$

$\mathrm{D}=$ kedalaman rata-rata

$\tau^{\prime} \quad=$ tegangan geser

$\tau \mathrm{ci}=$ tegangan geser kritis

$\mathrm{U}^{*}=$ kecepatan geser

$\omega \mathrm{i}=$ kecepatan jatuh partikel sedimen ukuran $\mathrm{i}$

Dengan penyederhanaan geometri sungai diasumsikan berbentuk trapesium (Gambar 20) dengan data sebagai berikut

Lebar sungai $B=145 \mathrm{~m}$

Kemiringan tebing sungai $=\mathrm{m}=1$

Ukuran partikel median $=\mathrm{d} 50=0.181 \mathrm{~mm}$

Kemiringan $=\mathrm{S}=0,0032$

Rapat masa sedimen $=\rho s=2731 \mathrm{~kg} / \mathrm{m} 3$

Luas penampang basah $\mathrm{A}=(\mathrm{b}+\mathrm{mh}) \mathrm{h}$

$$
=(475,722+1 \times 1,874) \times 1,874=894,878 f t^{2}
$$

Keliling basah $\mathrm{P}=\mathrm{b}+2 \mathrm{~h} \sqrt{ }\left(\mathrm{m}^{\wedge} 2+1\right)$

$$
=475,722+2 \times 1,874 \sqrt{1^{2}+1}=481,021 \mathrm{ft}
$$

Jari-jari hidrolis, $\mathrm{R}=\mathrm{A} / \mathrm{P}=894,878 / 481,021=1,86 \mathrm{ft}$

Nilai $R$ yang mendekati nilai h menunjukkan bahwa saluran tergolong saluran lebar sekali (wide channel) yang jika lebar sungai 5 hingga 10 kali kedalaman airnya maka besar jari-jari hidrolisnya sama dengan kedalaman alirannya [5].

Kecepatan rata-rata, $\mathrm{V}=\mathrm{Q} / \mathrm{A}=2530,296 / 894,878=2,828 \mathrm{ft} / \mathrm{s}$

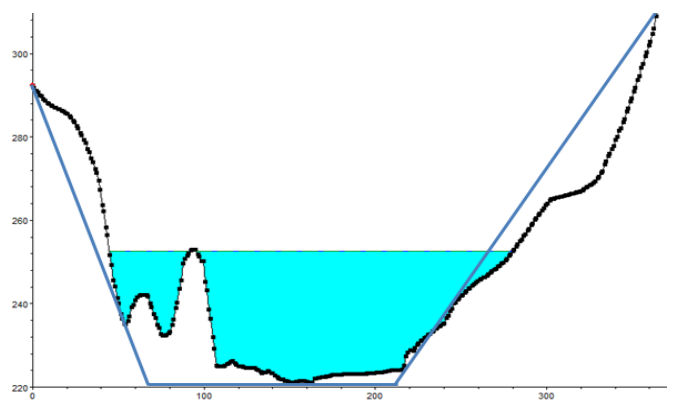

Gambar 20. Potonngan Melintang RS31.

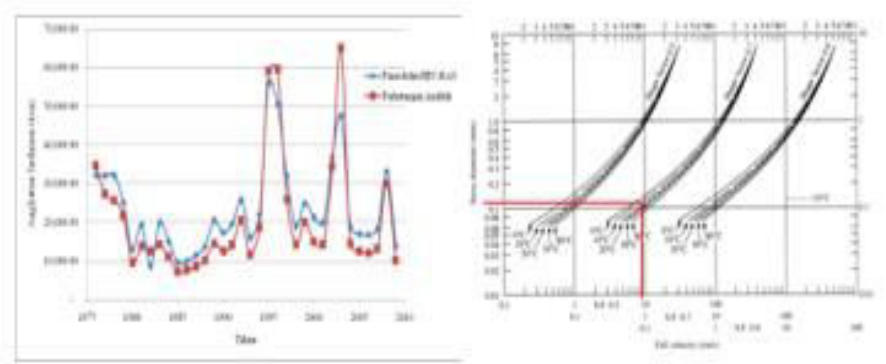

Gambar 21. Grafik Perbandingan Angkutan Sedimen per Tahun dan Hubungan ukuran diameter dan kecepatan jatuh. 


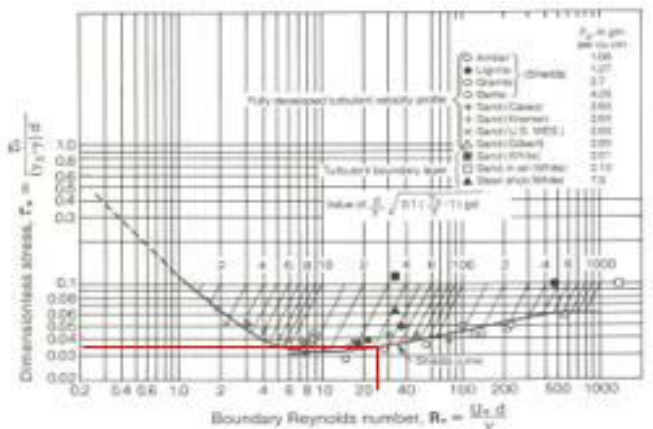

Gambar 22. Diagram Shield.

KeofisienManning $n=\frac{1.86^{2} / 3 \times 0.00325^{1 / 2}}{2,828}=0.03$

Kecepatan jatuh dari Gambar 21. Untuk diameter 0,181 $\mathrm{mm}$, suhu air $25 \mathrm{C}$, dan shape factor diasumsikan 0,7 karena pasir alami maka diperoleh kecepatan jatuh $=\omega=27 \mathrm{~cm} / \mathrm{s}$

Kecepatan geser $U^{*}=\sqrt{ }($ g.D. $S)=0.443$

Angka Reynold, $\mathrm{R}_{\mathrm{e}}=\frac{U_{*} \cdot \mathrm{d}_{50}}{v}=\frac{0,443 \times 5,94 \times 10^{-4}}{1,08 \times 10^{-5}}=24.424$

Tegangan geser dihitung dengan persamaan

$\tau^{\prime}=\frac{\rho \mathrm{V}^{2}}{58}\left(\frac{\mathrm{d}_{50}}{\mathrm{D}}\right)^{1 / 3}=0.587 \mathrm{lb} / \mathrm{ft} 2$

dimana $\tau^{\prime}=$ tegangan geser

$\rho=$ berat jenis air

$\mathrm{V}=$ kecepatan aliran

d_50= ukuran partikel sedimen berpresentase 50\%

$\mathrm{D}=$ kedalaman rata-rata

$\tau \mathrm{c}$ dari diagram Shielddiperoleh besar $\tau^{*}=0.035$ (Gambar22)

Tegangan geser krits, i $\tau c=\tau *\left(\gamma_{\mathrm{s}}-\gamma\right) \cdot \mathrm{d}_{50}$

$=0,035(170,491-62,428) \cdot 5,94 \cdot 10^{-4}=0.00225 \mathrm{lb} / \mathrm{dt} 2$

Sedangkan parameter $\mathrm{f}\left(\frac{\mathrm{U}_{*}}{\omega_{\mathrm{i}}}\right)$ diperoleh dari Gambar 23

Dimana $\frac{\mathrm{U}_{*}}{\omega_{\mathrm{i}}}=\frac{0,443}{0,886}=0.499$

diperoleh $\mathrm{f}\left(\frac{\mathrm{U}_{*}}{\omega_{\mathrm{i}}}\right)=10$

Konsentrasi Sedimen, $\mathrm{C}_{\mathrm{t}}=0,01 \times 61,428\left(\frac{5,94 \times 10^{-4}}{1,478}\right)^{7 / 6} \times$ $\left(\frac{0,587}{0,00225}-1\right) \times 10=0,138 \mathrm{lb} / \mathrm{ft}=2217 \mathrm{ppm}=2.217 \mathrm{~kg} / \mathrm{m}^{3}$

Debit muatan sedimen per satuan lebar penampang

$q t=q \times C t=0,494 \times 2,217=1,096 \mathrm{~kg} / \mathrm{s} / \mathrm{m}$

D. Perbandingan Pemodelan HEC-RAS dengan Perhitungan Analitik

Dari tabel 1 dan grafik diatas (Gambar 21) terlihat bahwa konsentrasi sedimen hasil perhitungan analitik cenderung lebih kecil dibanding hasil pemodelan dengan HEC-RAS. Hal ini dikarenakan pada perhitungan analitik ada penyederhanaan geometri seperti bentuk cross section sungai, lebar penampang melintang, kemiringan tebing sungai, dan kemiringan sungai. Sedangkan pada HEC RAS geometri sungai lebih detail.

Tabel 1.

Nilai angkutan sedimen hasil perhitungan analitik dan pemodelan HEC-RAS dalam satuan ton

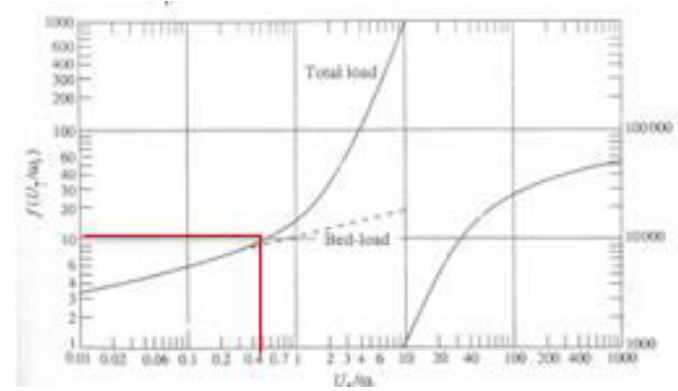

Gambar 23. Fungsi $\mathrm{f}\left(\mathrm{U}^{*} / \omega \mathrm{\omega}\right)$ berdasarkan Laursen.

\begin{tabular}{rrrrrr}
\hline \multirow{2}{*}{ Tahun } & $\begin{array}{r}\text { Pemodelan } \\
\end{array}$ & Perhitungan & \multirow{2}{*}{ Hahun } & Pemodelan & Perhitungan \\
HEC-RAS & Analitik & Analitik \\
\hline 1976 & $32,155.11$ & $34,548.14$ & 1993 & $15,984.83$ & $11,654.97$ \\
1977 & $32,072.08$ & $27,268.98$ & 1994 & $21,951.97$ & $18,703.11$ \\
1978 & $32,122.00$ & $25,692.63$ & 1995 & $56,023.15$ & $59,205.80$ \\
1979 & $25,131.88$ & $21,686.00$ & 1996 & $50,575.14$ & $59,491.25$ \\
1980 & $12,987.67$ & $9,557.29$ & 1997 & $31,926.42$ & $26,014.58$ \\
1981 & $19,329.06$ & $13,795.08$ & 1998 & $18,923.52$ & $14,216.15$ \\
1982 & $8,593.45$ & $12,473.53$ & 1999 & $24,980.11$ & $20,149.22$ \\
1983 & $19,932.01$ & $14,272.05$ & 2000 & $21,234.18$ & $15,031.50$ \\
1984 & $15,036.31$ & $10,990.13$ & 2001 & $19,929.14$ & $14,226.57$ \\
1985 & $9,501.15$ & $7,263.92$ & 2002 & $36,849.29$ & $34,280.19$ \\
1986 & $10,036.71$ & $7,604.86$ & 2003 & $47,413.37$ & $65,030.10$ \\
1987 & $11,416.59$ & $8,508.96$ & 2004 & $18,995.40$ & $14,398.85$ \\
1988 & $13,707.39$ & $10,121.84$ & 2005 & $16,973.48$ & $12,490.87$ \\
1989 & $20,503.68$ & $14,569.09$ & 2006 & $16,753.80$ & $12,114.69$ \\
1990 & $17,269.35$ & $12,473.53$ & 2007 & $18,407.37$ & $13,240.14$ \\
1991 & $19,567.64$ & $14,104.56$ & 2008 & $33,162.06$ & $30,130.76$ \\
1992 & $25,821.65$ & $20,329.45$ & 2009 & $13,847.10$ & $10,174.95$ \\
\hline
\end{tabular}

(Sumber: Hasil Perhitungan)

\section{KESIMPULAN}

1. Berikut merupakan pemodelan yang dilakukan untuk angkutan sedimen pada Bendungan Tugu menggunakan model HEC-RAS antara lain:

a. Pemodelan pertama, memodelkan geometri sungai dengan tiga reach di daerah genangan sebagai river station dan bendungan pada inline structure dengan hasil sedimentasi hanya terjadi di reach hulu.

b. Pemodelan kedua, memodelkan sama sebagaimana model pertama namun dengan penambahan pelimpah pada inline structure, yang kemudian hasil sedimen tetap terjadi di hulu saja meski sedimentasi yang terjadi lebih besar dan lebih ke hulu.

c. Pemodelan ketiga, memodelkan sebagaimana model kedua, namun dua reach daerah hulu dihapus sehingga hanya ada satu reach hilir. Output sedimentasi pada model ini hanya pada bagian hulu tampungan dan kecil nilainya.

d. Pemodelan keempat, dilakukan sama dengan pemodelan ketiga dengan penambahan culvert pada inline structure sebagai saluran pengambilan dan perubahan max depth menjadi $0 \mathrm{~m}$ pada sediment data karena merupakan model sedimentasi. Hasil model ini adalah sedimentasi yang terjadi berjalan hampir sampai ke bagian hilir namun muka air turun setinggi elevasi culvert dari waktu pertama dikarenakan besar outflow 
yang lebih dominan.

e. Pemodelan kelima, merupakan alternatif lain dari model keempat. Model ini sama dengan model ketiga namun pada cross section hulu bendungan dimasukkan lateral flow series dimana debitnya merupakan debit pengambilan yang bertanda negatif. Output yang dihasilkan hampir sama dengan pemodelan ketiga, dimana sedimentasi kecil pada bagian hulu.

f. Pemodelan kelima merupakan lanjutan dari pemodelan keempat, namun besar debit awal dibesarkan dengan asumsi bahwa waduk diisi terlebih dahulu hingga penuh baru dioperasikan. Hasil pemodelan ini tidak berbeda jauh dengan pemodelan keempat namun muka air waduk tidak turun di awal.

2. Perhitungan analitik dihitung menggunakan metode total load Laursen yang sama digunakan dalam pemodelan HEC-RAS. Perhitungan analitik dilakukan pada river station hulu. Hasil dari perhitungan analitik adalah konsentrasi sedimen dan debit angkutan sedimen, sedangkan yang dibandingkan dengan pemodelan HECRAS adalah besar angkutan sedimen. Besar angkutan sedimen hasil perhitungan analitik cenderung lebih kecil dibanding pemodelan HEC-RAS, dimana perkiraan besar laju sedimentasi dari metode pemodelan HEC-RAS sebesar $22.000 \mathrm{~m} 3 /$ th sedangkan laju sedimentasi hasil perhitungan analitik sebesar $19.400 \mathrm{~m} 3 /$ th. Perbedaan hasil ini dikarenakan pada perhitungan analitik terdapat penyederhanaan geometri seperti penampang melintang, kemiringan tebing sungai, kemiringan sungai, dan lain sebagainya. Sedangkan pada HEC RAS meski geometri sungai lebih detail, pemodelan masih berupa satu dimensi.

3. Keterbatasan pemodelan angkutan sedimen menggunakan HEC-RAS antara lain:

a. Pemodelan ini merupakan analisis satu dimensi, yang artinya kecepatan aliran di satu penampang melintang merupakan kecepatan rata-rata, sedangkan kenyataannya dalam satu penampang melintang kecepatan aliran dapat berbeda-beda. Hal ini menyebabkan sedimentasi yang tergambarkan tidak sesuai dengan teori yang ada.

b. Diperlukannya data yang lebih lengkap dibanding jika menghitung secara analitik seperti data suhu air, data geometri, dan data hubungan debit dengan konsentrasi sedimen.

Kelebihan pemodelan angkutan sedimen menggunakan HEC-RAS antara lain:

a. Memiliki tingkat akurasi yang baik terutama dari segi geometri sungai.

b. Besar sedimentasi setiap waktunya dapat dilihat dengan jelas baik berupa gambar, grafik maupun tabel besarnya sedimentasi.

c. Untuk menyimulasikan sedimentasi pada bendungan menggunakan software HEC-RAS, apabila terdapat alternatif desain maka dapat disimulasikan dengan cepat.

\section{DAFTAR PUSTAKA}

[1] Dep.PU Balai Besar Wilayah Sungai Brantas, "Laporan Akhir Pekerjaan Proyek Pembangunan Bendungan Tugu," Trenggalek, 2010.

[2] Dep.PU Dirjen Sumber Daya Air, "Pedoman Pengelolaan Sedimentasi Waduk," Jakarta, 2004.

[3] Hydrologic Engineering Center, "HEC-RAS River Analysis System, Application Guide, Version 5.0, February 2016. U.S. Army Cormps of Engineers," Davis, 2016.

[4] C. T. Yang, Sediment Transport Theory and Practice. New York, 1996.

[5] Anggrahini, Hidrolika Saluran Terbuka. Surabaya, 1997. 